\title{
Republicação das Demonstrações Contábeis: Uma Análise sob a perspectiva dos indicadores de desempenho
}

\author{
Sabrina da Silva Campos \\ MBA em Controladoria e Finanças pela Fundação Getúlio Vargas - FGV \\ Profissão e endereço: \\ E-mail:sabrinascampos@outlook.com.br \\ Roberto Miranda Pimentel Fully \\ Doutorado em Contabilidade pela Fucape Business School \\ Professor das Faculdades Integradas de Caratinga e das Faculdades Unificadas \\ Doctum de Manhuaçu. Conselheiro do Conselho de Administração do Grupo Light S/A \\ Condomínio Edifício Estamparia, R. da Consolação, 37. Consolação. São \\ Paulo/SP. CEP: 01.301-000 \\ E-mail: rfully@gmail.com \\ Aucione Aparecida Barros Guimarães \\ MBA em Controladoria e Finanças \\ Contadora Pública \\ Professora dos Cursos de Administração e Ciências Contábeis das Faculdades \\ Doctum de Manhuaçu \\ Avenida Getúlio Vargas, 700. Coqueiro. Manhuaçu/MG. CEP: 36.900-000 \\ E-mail:aucione@doctum.edu.br
}

\section{RESUMO}

A avalanche de escândalos contábeis dos últimos anos resultou na perda de confiança do público perante as grandes empresas. Os investidores perdem a confiança na gestão das empresas nos casos em que os escândalos são acompanhados de reformulações e republicações das informações contábeis. Para resguardar a integridade das demonstrações e preservar os investidores, a CVM determina a republicação das demonstrações com as devidas correções. Esta pesquisa analisa os impactos das republicações das demonstrações contábeis nos índices ROE (Retorno sobre o patrimônio), ROA (Retorno sobre ativos) e ET (Endividamento Total) nas empresas brasileiras, no período de 2000 a 2013, abordando a adoção do IFRS no Brasil a partir de 2007. Esta pesquisa não tinha como objetivo evidenciar o erro nas demonstrações que implicaram as republicações; no entanto, o gerenciamento de resultados compromete as informações contidas nos demonstrativos contábeis divulgados, podendo impactar na decisão dos investidores. Foram constatados impactos negativos nos índices, devido a um aumento no índice ET (8\%), e reduções no índice ROE (22,9\%). No índice ROA, foi constatado aumento (34,5\%); no entanto, o índice se manteve negativo. Os resultados gerais do estudo estão em concordância com a revisão teórica desenvolvida nesta pesquisa, pois todos os estudos evidenciados indicaram impactos negativos após as republicações. 
Republicação das Demonstrações Contábeis: Uma Análise sob a perspectiva dos indicadores de desempenho

Sabrina da Silva Campos, Roberto Miranda Pimentel Fully, Aucione Aparecida Barros Guimarães

Palavras-Chave: ROA. ROE. Republicações Contábeis. Disclosure. Accruals e IFRS.

\section{Republication of Financial Statements: An Analysis from the perspective of performance indicators}

\section{ABSTRACT}

The avalanche of accounting scandals in recent years has resulted in the loss of public confidence in large companies. Investors lose confidence in the management of companies in cases where scandals are accompanied by reformulations and republishing's of accounting information. In order to safeguard the integrity of the statements and preserve investors, the CVM determines the republication of the statements with the necessary corrections. This research analyzes the impacts of the republished financial statements on the ROE (Return on Equity), ROA (Return on Assets) and Debt ratio in Brazilian companies, from 2000 to 2013, addressing the adoption of IFRS in Brazil from 2007. This research did not aim to show the error in the statements that resulted in the re-publication, however, earnings management compromises the information contained in the published financial statements, which may impact the decision of investors. Negative impacts were noted in the indices, due to an increase in the ET index (8\%), and reductions in the ROE index (22.9\%). The ROA index showed an increase (34.5\%), however, the index remained negative. The general results of the study are in agreement with the theoretical review developed in this research, since all the studies evidenced indicated negative impacts after the republishing's.

Keywords: ROA. ROE. Republications Accounting. Disclosure. Accruals and IFRS.

\section{INTRODUÇÃO}

A avalanche de escândalos contábeis dos últimos anos resultou na perda de confiança do público perante as grandes empresas. Lassen, Gertsen e Riis (2006) afirmam que os investidores perdem a confiança na gestão das empresas nos casos em que os escândalos são acompanhados de reformulações e republicações das informações contábeis.

Angeli (2008) alega que os escândalos contábeis evidenciam a importância da transparência e qualidade da informação contábil, visto que as informações refletidas 
Republicação das Demonstrações Contábeis: Uma Análise sob a perspectiva dos indicadores de desempenho

Sabrina da Silva Campos, Roberto Miranda Pimentel Fully, Aucione Aparecida Barros Guimarães

nas demonstrações devem apresentar a realidade econômica, financeira e patrimonial da empresa.

Assim sendo, de acordo com Schipper (2003), a informação contábil só será útil para o processo decisório se atentar a requisitos como: (i) relevância; (ii) apresentação adequada; (iii) verificável; (iv) neutra; (v) não enviesada; (vi) comparável; e (vii) confiável.

Contudo, os recentes acontecimentos de fraudes e/ou erros nas demonstrações têm levado à perda de credibilidade e confiabilidade da informação contábil. Para resguardar a integridade das demonstrações e preservar os investidores, a CVM determina a republicação das demonstrações com as devidas correções.

Assim, o problema da pesquisa tem como alicerce a seguinte pergunta: Qual o impacto das republicações das demonstrações contábeis nos índices ROE, ROA e Endividamento Total?

Para responder a questão proposta, esta pesquisa analisa os impactos das republicações das demonstrações contábeis nos índices ROE, ROA e Endividamento Total nas empresas brasileiras e, com o intuito de dar continuidade ao estudo de Angeli (2008), esta pesquisa abrange o período de 2000 a 2013, abordando a adoção do IFRS no Brasil a partir de 2007.

De acordo com Soderstrom e Sun (2007), a adoção do IFRS seria uma maneira de consolidar e aumentar a qualidade das informações contábeis. No entanto, a qualidade das informações também está ligada ao ambiente em que a entidade está inserida, incluindo o sistema jurídico e político de cada país.

A correção e republicação das demonstrações contábeis podem acarretar aumentos ou diminuições no resultado das empresas. Os efeitos das republicações afetam não só o resultado, como também a imagem da empresa e da contabilidade, visto que este é um problema real vivido na atualidade. Esta pesquisa é de grande importância para o mercado brasileiro.

A pesquisa se limita às republicações obrigatórias determinadas pela CVM durante o período de 2000 a 2013, não abrangendo notificações de períodos anteriores 
Republicação das Demonstrações Contábeis: Uma Análise sob a perspectiva dos indicadores de desempenho

Sabrina da Silva Campos, Roberto Miranda Pimentel Fully, Aucione Aparecida Barros Guimarães

a 2000 nem posteriores a 2013. Em decorrência do modelo econométrico proposto, esta pesquisa tem limitação dos testes em decurso de restrição temporal.

\section{REPUBLICAÇÃO DAS DEMONSTRAÇÕES CONTÁBEIS}

De acordo com a NBC TG 26(R3) - Apresentação das Demonstrações Contábeis (2015), quando a entidade omitir ou divulgar informações distorcidas a ponto de influenciar a decisão econômica dos usuários das demonstrações contábeis, ou quando a entidade não aplicar um requisito de norma, interpretação ou comunicado técnico, de maneira que este procedimento possa afetar os montantes reconhecidos em período corrente, a entidade deverá proceder à republicação, divulgando os impactos financeiros da não aplicação da norma, interpretação ou comunicado técnico.

Assim, Anderson e Yohn (2002), em sua pesquisa, investigaram os efeitos das republicações no valor da empresa e a confiança dos investidores nos resultados da empresa; no entanto, chegaram à conclusão de que tanto a confiança dos investidores quanto o valor da empresa se reduzem após as republicações.

Palmrose, Richardson e Scholz (2004) analisaram uma amostra de 225 empresas sujeitas à regulamentação da SEC, que republicaram suas demonstrações contábeis no período de 1971 a 2000. Como resultado, identificaram que essas empresas obtiveram reações negativas perante o mercado, além de apresentarem um endividamento mais elevado.

Hribar e Jenkins (2004) estudaram a reação dos investidores quanto às republicações e obtiveram evidências de que os investidores têm uma visão negativa e reduzem seus investimentos após as republicações das informações contábeis.

E, com o intuito de verificar o efeito do refazimento das demonstrações contábeis sobre o custo de capital, os autores analisaram uma amostra de 292 refazimentos no período de 1997 a 2001. Os resultados apurados identificaram que as republicações implicam uma diminuição nos lucros futuros das empresas e um aumento de custo de capital. 
Republicação das Demonstrações Contábeis: Uma Análise sob a perspectiva dos indicadores de desempenho

Sabrina da Silva Campos, Roberto Miranda Pimentel Fully, Aucione Aparecida Barros Guimarães

De acordo com os autores citados acima, as republicações das demonstrações contábeis implicam uma restrição da qualidade da estimativa de ganhos esperados da empresa e, consequentemente, aumentam as taxas de retorno exigidas pelos investidores.

Palmrose, Richardson e Scholz (2004) pesquisaram as reações do mercado após o anúncio da republicação nos anos de 1994 a 2004. Analisaram uma amostra de 403 anúncios de republicações e identificaram reações negativas do mercado. Os retornos negativos estavam associados às republicações que envolviam fraudes que afetavam um maior número de contas.

Callen, Livnat e Segal (2005) examinaram os efeitos das republicações sobre os investidores e comprovaram que os investidores veem as republicações negativamente, evidenciando três motivos: (i) as republicações causam previsões negativas nos fluxos de caixa futuros; (ii) as empresas que republicaram apresentam uma contabilidade fraca ou sistemas informacionais insuficientes; e (iii) comportamento oportunista dos gerentes com o intuito de aumentar os lucros reportados a partir de métodos inaceitáveis.

Bischoff, Finley e Leblanc (2008) ressaltam que os principais motivos que levam às republicações das demonstrações contábeis estão ligados ao reconhecimento impróprio de receitas e despesas, erros de capital vinculados ao reconhecimento de remuneração de ações e erros de classificação contábil, e atestam que o refazimento e a republicação das demonstrações contábeis patenteiam reflexos negativos por afetarem a confiança dos investidores.

De forma geral, os estudos relacionados ao tema desta pesquisa indicam que o refazimento e a republicação das demonstrações contábeis impactam negativamente as empresas.

\subsection{Disclosure}

A NBC TG 40(R2) - Instrumentos Financeiros: Evidenciação (2015) tem como objetivo exigir que as entidades divulguem, em suas demonstrações contábeis, informações adequadas, de forma que os usuários internos e externos possam avaliar a 
Republicação das Demonstrações Contábeis: Uma Análise sob a perspectiva dos indicadores de desempenho

Sabrina da Silva Campos, Roberto Miranda Pimentel Fully, Aucione Aparecida Barros Guimarães

relevância do instrumento financeiro tanto para a posição patrimonial e financeira, quanto para o desempenho da entidade; e também a natureza e a proporção dos riscos resultantes de instrumentos financeiros.

Land e Lundholm (1996) afirmam que, em empresas que trabalham com políticas de disclosure (divulgação) mais informativo, as previsões de estimativas de lucros são mais precisas. Obtêm menor dispersão entre as previsões dos analistas individuais e uma menor volatilidade nas revisões de previsão.

De acordo com Silva (1999), o disclosure, que integra o terceiro pilar da contabilidade, auxilia na avaliação da atual situação da entidade, ensejando prognósticos futuros por permitir uma maior maleabilidade na formação das informações, sejam elas de natureza econômica, financeira ou patrimonial.

No Brasil, a Lei 11.638/07, que dispõe sobre as Sociedades por Ações, juntamente com a NBC TG 26(R3) - Apresentação das Demonstrações Contábeis, determinam um conjunto de informações que devem ser fornecidas pelas empresas para atender as necessidades dos usuários externos, divulgando demonstrações que explicitam a realidade econômica, patrimonial e financeira das entidades.

\subsection{International Financial Reporting Standards (IFRS)}

De acordo com (Soderstrom e Sun, 2007), a adoção do IFRS seria uma maneira de consolidar e aumentar a qualidade das informações contábeis. Em concordância com este pensamento, Ewert e Wagenhofer (2005) evidenciam que compactar os padrões contábeis pode reduzir os níveis de gerenciamento de resultados e melhorar a qualidade das informações divulgadas nos relatórios.

Lambert, Leuz e Verrecchia (2007) afirmam que a inserção obrigatória do IFRS se associa a um aumento de liquidez de mercado e também a um declínio do custo de capital das empresas, pois quanto maior a qualidade das informações e da divulgação, menores serão os problemas no mercado de ações e os riscos de estimativas.

Para Daske, Leuz e Verdi (2008), a adoção do IFRS pelas empresas ao redor do mundo é uma das modificações normativas mais significantes para a história da 
Republicação das Demonstrações Contábeis: Uma Análise sob a perspectiva dos indicadores de desempenho

Sabrina da Silva Campos, Roberto Miranda Pimentel Fully, Aucione Aparecida Barros Guimarães

contabilidade. De acordo com os autores, espera-se que, com o uso do IFRS, aumente a comparabilidade das demonstrações financeiras, a qualidade da transparência e a qualidade da informação financeira, beneficiando assim os investidores.

Daske et al. (2008) afirmam que outro efeito positivo da adoção obrigatória do IFRS seria a redução da quantidade de relatórios em relação aos GAAPs, uma vez que o IFRS obriga as empresas a seguirem um padrão de elaboração, melhorando seus relatórios.

Igualmente, mesmo que a qualidade dos relatórios das empresas não melhore com o uso do IFRS, os relatórios financeiros fornecidos serão mais úteis para os investidores, por utilizarem um conjunto comum de normas contábeis, facilitando os investidores na diferenciação de empresas com maior e menor qualidade, reduzindo a assimetria informacional entre os investidores.

No Brasil, com a aprovação da Lei 11.638/07, foi determinada a adoção do IFRS para as companhias abertas. De acordo com Pires, Decourt e Camargo (2012), a inserção do IFRS às companhias brasileiras ocorreu em duas fases: a primeira, parcial, em 2008, e a segunda, integral, em 2010. A partir desse período, passou a ser obrigatória a utilização dos critérios internacionais para a elaboração das demonstrações contábeis.

O IAS 1 - Apresentação das Demonstrações Contábeis dispõe sobre a elaboração e divulgação das demonstrações contábeis pelas entidades. De acordo com o IAS 1, o conjunto de demonstrações contábeis deve incluir: "(i) Balanço Patrimonial; (ii) Demonstração do Resultado do Exercício; (iii) Demonstração das Mutações do Patrimônio Liquido; (iv) Demonstração dos Fluxos de Caixa; e (v) Notas Explicativas".

Segundo o IAS 1, as demonstrações contábeis devem conter características gerais, como: "(i) apresentação justa e em conformidade com os IFRS; (ii) pressuposto de continuidade; (iii) regime de competência; (iv) consistência de apresentação; (v) materialidade e agregação; (vi) não compensação de ativos e passivos; e (vii) informação comparativa". 
Republicação das Demonstrações Contábeis: Uma Análise sob a perspectiva dos indicadores de desempenho

Sabrina da Silva Campos, Roberto Miranda Pimentel Fully, Aucione Aparecida Barros Guimarães

\subsection{Accruals}

De acordo com a NBC TG ESTRUTURA CONCEITUAL - Estrutura Conceitual para Elaboração e Divulgação de Relatório Contábil-Financeiro, os accruals (acréscimos) ou performance financeira são resultantes de mudanças nos recursos econômicos da entidade e não da aquisição direta de investidores e credores. Assim os accruals são úteis para avaliar a capacidade passada e futura da entidade de gerar fluxos de caixa líquidos.

Dichev (2002) argumenta que os accruals podem ajustar o reconhecimento de fluxos de caixa ao longo do tempo, fazendo com que os resultados contábeis se tornem uma melhor medida de desempenho das empresas.

Chen, Tang, Jiang e Lin (2010) afirmam que, após a adoção obrigatória do IFRS, houve uma melhora na contabilidade. Os autores encontraram evidências de uma diminuição no gerenciamento de resultados, uma diminuição nos accruals discricionários e uma diminuição no desvio padrão de accruals inexplicáveis; no entanto, constatou também uma diminuição na probabilidade de reconhecimento de perdas.

Zang (2012) assevera que a gestão de rendimentos reais antecede a decisão de gerenciar os lucros por meio de accruals e que as estratégias de gestão dos dois ganhos podem atuar como substitutos; no entanto, a manipulação do exercício-base e dos ganhos reais está negativamente correlacionada.

\section{METODOLOGIA}

Esta pesquisa se baseia em um modelo experimental, com caráter exploratório, envolvendo um propósito descritivo, abordando o método quantitativo.

Assim, esta pesquisa analisa republicações das demonstrações contábeis no âmbito brasileiro, no período de 2000 a 2013. A amostra de republicações das demonstrações contábeis foi coletada no site da CVM mediante a opção "Determinação de Refazimento e Republicação das Demonstrações Contábeis". 
Republicação das Demonstrações Contábeis: Uma Análise sob a perspectiva dos indicadores de desempenho

Sabrina da Silva Campos, Roberto Miranda Pimentel Fully, Aucione Aparecida Barros Guimarães

Para alcançar o objetivo principal, foram analisados os índices ROA, ROE e ET.

O índice ROA - Retorno sobre o Ativo é calculado a partir da Equação 1:

$$
R O A=\frac{\text { Lucro Operacional }}{\text { Ativo Total }}
$$

O índice ROE - Retorno sobre o Patrimônio Líquido é calculado de acordo com a Equação 2, a seguir:

$$
R O E=\frac{\text { Lucro Líquido }}{\text { Patrimônio Líquido }}
$$

O Endividamento Total é representado pela Equação 3:

$$
E T=\frac{\text { Passivo Circulante }+ \text { Passivo Não Circulante }}{\text { Ativo Total }}
$$

De acordo com (Assaf Neto, 2006), o ROA é um dos mais importantes indicadores de rentabilidade de uma entidade, sendo obtido da relação entre o Lucro Operacional e o Ativo Total. O ROE é a rentabilidade sobre o capital próprio investido na entidade, sendo obtido pela relação do Lucro Líquido, após o IR, e o Patrimônio Líquido. O Endividamento Total define o grau de endividamento da empresa, ou seja, o quanto a empresa utiliza de capital de terceiros.

A escolha dos índices ROA, ROE e ET se justifica na hipótese de que os investidores têm uma melhor visão das empresas que mantêm bons níveis de rentabilidade e de capacidade de pagamento de dívidas; no entanto, são acontecimentos distintos. 
Republicação das Demonstrações Contábeis: Uma Análise sob a perspectiva dos indicadores de desempenho

Sabrina da Silva Campos, Roberto Miranda Pimentel Fully, Aucione Aparecida Barros Guimarães

Os índices ROA, ROE e ET foram calculados nas demonstrações originais da amostra e, posteriormente, nas demonstrações republicadas, permitindo comparação entre os índices.

A estatística descritiva e a análise de Médias, Variâncias, Covariâncias, Desvio Padrão, Desvio Médio, Distorção e Inclinação foram utilizadas para equiparar os resultados, dando sustentação às conclusões desta pesquisa.

De acordo com Larson e Farber (2010), a Média é definida como a soma dos dados da amostra dividida pelo número de dados constantes na amostra, sendo representada pela Equação 4:

$$
\mu=\frac{\sum x}{N}
$$

A Variância é definida como a soma dos quadrados do desvio em relação à sua média dividida pelo número de observações do conjunto menos uma, sendo calculada a partir da Equação 5:

$$
s^{2}=\sum_{i=1}^{n} \frac{\left(x_{i}-\bar{x}\right)^{2}}{n-1}
$$

A covariância é definida como uma medida de dependência linear entre duas variáveis. Seu coeficiente de Correlação Linear varia entre -1 e 1, indicando o grau de dependência, sendo calculada pela Equação 6:

$$
\operatorname{Cov}(X, Y)=\frac{\sum_{i=1}^{n}\left(x_{i}-\bar{x}\right)\left(y_{i}-\bar{y}\right)}{n}
$$


Republicação das Demonstrações Contábeis: Uma Análise sob a perspectiva dos indicadores de desempenho

Sabrina da Silva Campos, Roberto Miranda Pimentel Fully, Aucione Aparecida Barros Guimarães

O Desvio Padrão amostral de um conjunto é igual à raiz quadrada da Variância amostral. O Desvio Padrão é dado pela Equação 7:

$$
s=\sqrt{s^{2}}=\sqrt{\sum_{i=1}^{n} \frac{\left(x_{i}-\bar{x}\right)^{2}}{n-1}}
$$

O Desvio Médio é uma medida de dispersão dos dados em relação à média. Representa a distância de cada elemento da amostra e seu valor médio. O Desvio médio é calculado a partir da Equação 8:

$$
D M=\frac{\sum\left|x_{i}-\bar{x}\right|}{n}
$$

A Distorção é caracterizada pelo grau de assimetria de distribuição em torno da média, sendo calculada pela Equação 9:

$$
\frac{n}{(n-1)(n-2)} \sum\left(\frac{x_{i}-\bar{x}}{s}\right)^{3}
$$

A Inclinação é a distância vertical dividida pela distância horizontal entre pontos na linha. É a taxa de mudança ao longo da linha de regressão. A equação para a inclinação na linha de regressão é representada pela Equação 10:

$$
b=\frac{\sum(x-\bar{x})(y-\bar{y})}{\sum(x-\bar{x})^{2}}
$$

Para esta pesquisa, não foi possível capturar a influência da adoção da convergência contábil em 2008, em decorrência do tamanho da amostra. 
Republicação das Demonstrações Contábeis: Uma Análise sob a perspectiva dos indicadores de desempenho

Sabrina da Silva Campos, Roberto Miranda Pimentel Fully, Aucione Aparecida Barros Guimarães

Diferentemente do trabalho científico original, as informações estatísticas foram ampliadas com outros modelos de análise.

\subsection{Amostra}

A amostra foi baseada na pesquisa de Angeli (2008) e ampliada tanto na série temporal quanto em número de empresas, se comparada ao trabalho científico original, abrangendo o período de 2000 a 2013.

Foi constatado um total de 64 companhias, como mostra o Anexo I. O Anexo II mostra quais empresas republicaram suas demonstrações após o recebimento do ofício pela CVM.

Após a determinação da amostra, foram aplicados cálculos e análises de Média, Variância, Covariância, Desvio Padrão, Desvio Médio, Distorção e Inclinação sobre o percentual de empresas que republicaram como mostra o Anexo III. O percentual de republicação foi de aproximadamente $76 \%$ do total das empresas que receberam o ofício.

\section{ANÁLISE DOS RESULTADOS}

Após os cálculos dos índices ROA, ROE e ET, foram feitas análises de Média, Variância, Covariância, Desvio Padrão, Desvio Médio, Distorção e Inclinação, como mostra a Tabela 1 a seguir: 
Republicação das Demonstrações Contábeis: Uma Análise sob a perspectiva dos indicadores de desempenho

Sabrina da Silva Campos, Roberto Miranda Pimentel Fully, Aucione Aparecida Barros Guimarães

Tabela 1

Cálculo das Variáveis Estatísticas

\begin{tabular}{|c|c|c|c|c|c|}
\hline \multicolumn{2}{|r|}{ ROA } & \multicolumn{2}{|r|}{ ROE } & \multicolumn{2}{|r|}{ ET } \\
\hline 0,288269189 & 0,282226538 & 1,148970407 & 1,199825655 & 1,448952917 & 1,441838198 \\
\hline $\begin{array}{l}\text { Desvio } \\
\text { Padrão }\end{array}$ & $\begin{array}{l}\text { Desvio } \\
\text { Padrão }\end{array}$ & $\begin{array}{l}\text { Desvio } \\
\text { Padrão }\end{array}$ & Desvio Padrão & $\begin{array}{l}\text { Desvio } \\
\text { Padrão }\end{array}$ & Desvio Padrão \\
\hline 0,15564184 & 0,158180336 & 0,47501768 & 0,56430992 & 0,550853168 & 0,56533976 \\
\hline Desvio Médio & Desvio Médio & $\begin{array}{l}\text { Desvio } \\
\text { Médio }\end{array}$ & Desvio Médio & Desvio Médio & Desvio Médio \\
\hline 0,083099125 & 0,079651819 & 1,320132995 & 1,439581602 & 2,099464555 & 2,078897388 \\
\hline Variância & Variância & Variância & Variância & Variância & Variância \\
\hline \multicolumn{2}{|c|}{0,074302413} & \multicolumn{2}{|c|}{1,224097311} & \multicolumn{2}{|c|}{2,00664031} \\
\hline \multicolumn{2}{|c|}{ Covariância do ROA } & \multicolumn{2}{|c|}{ Covariância do ROE } & \multicolumn{2}{|c|}{ Covariância do ET } \\
\hline$-2,236989474$ & $-2,154451602$ & $-5,653045844$ & $-4,96829788$ & 6,307618526 & 6,245340718 \\
\hline Distorção & Distorção & Distorção & Distorção & Distorção & Distorção \\
\hline \multicolumn{2}{|c|}{0,951877683} & \multicolumn{2}{|c|}{0,867667999} & \multicolumn{2}{|c|}{0,984941424} \\
\hline \multicolumn{2}{|l|}{ Inclinação } & \multicolumn{2}{|c|}{ Inclinação } & \multicolumn{2}{|c|}{ Inclinação } \\
\hline$-0,0111016$ & $-0,0072648$ & $-0,1364158$ & $-0,1676502$ & 0,9424312 & 1,0188866 \\
\hline Média & Média & Média & Média & Média & Média \\
\hline
\end{tabular}

Nota. Fonte: Dados da pesquisa.

A Média do índice ROA variou de $-0,011$, antes das republicações, para $-0,007$ após as republicações, variação de aproximadamente $34,5 \%$, indicando que, após as republicações, o índice ROA se elevou. A Variância variou de 0,08 antes das republicações para 0,07 após as republicações. Ela estima a variação da amostra, reduzindo em, aproximadamente, 12,5\%.

A Covariância indica o grau de dependência entre as variáveis, variando entre -1 e 1. A Covariância do ROA indicou um grau de dependência de 0,07 em relação aos índices anteriores e posteriores às republicações, apresentando um grau de normalidade por estar entre os limites.

O Desvio Padrão mostra o quanto de variação ou dispersão existe em relação à média. No índice ROA, o Desvio Padrão variou de 0,29 para 0,28 , após as 
Republicação das Demonstrações Contábeis: Uma Análise sob a perspectiva dos indicadores de desempenho

Sabrina da Silva Campos, Roberto Miranda Pimentel Fully, Aucione Aparecida Barros Guimarães

republicações, reduzindo aproximadamente 3,4\%. O Desvio Médio calcula a dispersão dos dados em relação à média; o índice ROA apresentou um desvio médio de 0,155 antes e 0,158 após as republicações, aumentando em 1,93\% a dispersão dos dados.

A Distorção apresenta o grau de assimetria de distribuição em torno da média, e a Inclinação apresenta a taxa de mudança da linha de regressão. $O$ índice ROA apresentou uma distorção de -2,23 antes da republicação e -2,15 após as republicações, indicando uma distribuição com uma ponta assimétrica para valores mais negativos.

O coeficiente da Inclinação apresenta a inclinação na linha de regressão, ou seja, a distância vertical relacionada à distância horizontal; o índice ROA apresentou uma inclinação da reta de regressão linear de 0,95.

O índice ROE apresentou uma variação na média de aproximadamente $22,8 \%$; variou de -0,13 para -0,16, após as republicações, indicando que, após as republicações, o índice ROE ficou reduzido.

A Variância variou de 1,32 para 1,43, evidenciando um aumento na variação da amostra de 8,33\%. A Covariância do índice ROE apresentou um grau de dependência de 1,22, indicando um maior grau de dependência entre as variáveis, estando acima do limite da variação do coeficiente.

O Desvio Padrão variou de 1,14 para 1,19 após as republicações, indicando um aumento na dispersão dos dados em relação à média de 4,39\%. O Desvio Médio variou de 0,47 para 0,56, aumentando em aproximadamente 19\% a dispersão média dos dados.

O índice ROE apresentou uma Distorção de $-5,65$, antes das republicações, para -4,96 posteriormente, indicando uma redução no grau de assimetria de aproximadamente $12 \%$. O índice ROE apresentou uma inclinação da reta de regressão linear de 0,86 .

O índice ET apresentou uma média de 0,94 antes das republicações e evoluiu para 1,01 após as republicações, uma evolução de aproximadamente $8 \%$, indicando que os índices, após a republicação, aumentaram seus valores. 
Republicação das Demonstrações Contábeis: Uma Análise sob a perspectiva dos indicadores de desempenho

Sabrina da Silva Campos, Roberto Miranda Pimentel Fully, Aucione Aparecida Barros Guimarães

A Variância do índice ET passou de 2,09 para 2,07 após as republicações, indicando que a variação entre as variáveis reduziu em 0,95\%. A Covariância indicou um grau de dependência de 2,00, excedendo o limite do coeficiente em 100\%.

O Desvio Padrão mostra o quanto existe de dispersão entre as variáveis. No índice ET, o desvio padrão variou de 1,448 para 1,441, após as republicações, uma variação de aproximadamente $0,48 \%$. O Desvio Médio variou de 0,55 para 0,56 após as republicações, aumentando em aproximadamente $1,8 \%$ a variação média das variáveis.

A Distorção do índice ET apresentou uma variação de 6,30 pra 6,24 após as republicações, indicando uma redução no grau de assimetria de 0,95\%. Uma distorção com valores positivos indica que a distribuição assimétrica se estende para valores positivos. O índice de ET apresentou uma inclinação da reta de regressão linear de 0,98 .

As tabelas a seguir evidenciam o percentual de aumentos e reduções dos índices comparados com os índices após as republicações:

Tabela 2

Aumentos no índice ROA

\begin{tabular}{lcc}
\hline Empresas & & ROA \\
& Antes da republicação & Após a republicação \\
\hline Celesc & 0,02459 & 0,02578 \\
Celesc & $-0,04938$ & 0,03292 \\
Celesc & 0,03108 & 0,03292 \\
Varig & $-0,15093$ & $-0,14476$ \\
Varig & $-0,6279$ & $-0,35271$ \\
Cia. Cataguases & 0,08544 & 0,5554 \\
Mendes Junior & $-0,029$ & 0,09003 \\
Cesp & $-0,02474$ & $-0,02164$ \\
Abyara & 0,00312 & 0,02485 \\
Estrela & $-0,09352$ & $-0,03861$ \\
Hoteis Othon & $-0,49969$ & $-0,29494$ \\
CEEE-GT & 0,04233 & 0,04512 \\
Baesa & 0,076 & 0,07934 \\
L & $\mathbf{- 1 , 2 1 2 6}$ & $\mathbf{0 , 0 3 3 7}$ \\
\hline Média & $\mathbf{- 0 , 0 9 3 2 8}$ & $\mathbf{0 , 0 0 2 5 9 2}$ \\
\hline
\end{tabular}

Nota. Fonte: Dados da pesquisa. 
Republicação das Demonstrações Contábeis: Uma Análise sob a perspectiva dos indicadores de desempenho

Sabrina da Silva Campos, Roberto Miranda Pimentel Fully, Aucione Aparecida Barros Guimarães

A Tabela 2 demonstra que 13 empresas (26\%) que republicaram suas demonstrações obtiveram aumentos no índice ROA.

Tabela 3

Aumentos no índice ROE

\begin{tabular}{lcc}
\hline Empresas & & ROE \\
Celesc & Antes da republicação & Após a republicação \\
Paranapanema & $-0,0946$ & 0,03102 \\
Cemig & $-0,02721$ & 0,38223 \\
Arteb & $-0,17635$ & 0,03961 \\
Chiarelli & $-0,01956$ & 0,10702 \\
Gol & $-0,88688$ & 0,66195 \\
Teka & 0,31628 & 0,51041 \\
Excelsior & 0,07559 & 1,32171 \\
Predileto & 0,02774 & 0,06061 \\
Chiarelli & 0,25004 & 0,27519 \\
Mendes Júnior & 0,02773 & 0,0606 \\
Energisa & $-0,17065$ & 0,3007 \\
Hoteis Othon & $-0,08202$ & 0,36261 \\
Inepar Energia & $-1,80905$ & $-1,45697$ \\
Baesa & 0,23542 & 0,44524 \\
Minerva & 0,06275 & 0,07446 \\
$\Sigma$ & 0,05237 & 0,06808 \\
\hline Média & $-2,2184$ & 3,24447 \\
\hline
\end{tabular}

Nota. Fonte: Dados da pesquisa.

A Tabela 3 evidencia os aumentos no índice ROE que representaram $32 \%$ do total, ou seja, 16 republicações implicaram aumentos no ROE. 
Republicação das Demonstrações Contábeis: Uma Análise sob a perspectiva dos indicadores de desempenho

Sabrina da Silva Campos, Roberto Miranda Pimentel Fully, Aucione Aparecida Barros Guimarães

Tabela 4

Aumentos no índice ET

\begin{tabular}{lcc}
\hline Empresas & ET & Após a republicação \\
\hline Sutepa & 0,4866 & 0,55959 \\
Duke & 0,2893 & 0,40293 \\
Celesc & 0,63523 & 0,66601 \\
Celesc & 0,64243 & 0,64547 \\
Celesc & 0,62579 & 0,65641 \\
Paranapanema & 0,41672 & 0,94685 \\
Cemig & 0,58665 & 1,90895 \\
Wetzel & 0,91378 & 1,39766 \\
Arteb & 1,29343 & 1,60746 \\
Caraíba Metais & 0,59661 & 0,77921 \\
Chiarelli & 0,82061 & 1,43959 \\
Gol & 0,20907 & 0,59326 \\
Gol & 0,35034 & 0,35394 \\
Catagueses & 0,4829 & 0,49475 \\
Teka & 0,98052 & 1,13629 \\
Chiarelli & 1,9937 & 1,99937 \\
Excelsior & 0,78497 & 0,88322 \\
Predileto & 0,72137 & 0,81365 \\
Cia. Catagueses & 0,47393 & 0,50645 \\
Ivepar & 0,82061 & 1,43958 \\
Chiarelli & 0,74486 & 0,88322 \\
Parmalat & 0,8139 & 0,89218 \\
Cesp & 0,44038 & 0,50024 \\
Abyara & 0,85662 & 0,87672 \\
Americanas & 0,69283 & 0,70562 \\
Banco Cruzeiro & 0,82489 & 0,88559 \\
CEEE-D & 0,47948 & 0,59284 \\
CEEE-GT & 0,56542 & 0,62112 \\
Baesa & 0,42232 & 0,45416 \\
Minerva & 0,77238 & 0,82491 \\
DTCOM & 0,63287 & 0,70676 \\
Média & $\mathbf{2 1 , 3 7 0 5 1}$ & $\mathbf{2 7 , 1 7 4}$ \\
\hline & $\mathbf{0 , 6 8 9 3 7 1}$ & \\
\hline
\end{tabular}

Nota. Fonte: Dados da pesquisa.

De acordo com a Tabela 4, 31 empresas que republicaram suas demonstrações tiveram aumentos no índice de Endividamento Total, ou seja, $62 \%$ dos índices de Endividamento Total aumentaram após as republicações. 
Republicação das Demonstrações Contábeis: Uma Análise sob a perspectiva dos indicadores de desempenho

Sabrina da Silva Campos, Roberto Miranda Pimentel Fully, Aucione Aparecida Barros Guimarães

Tabela 5

Reduções no índice ROA

\begin{tabular}{lcc}
\hline \multicolumn{1}{c}{ Empresas } & & ROA \\
Sultepa & Antes da republicação & Após a republicação \\
Duke & 0,00361 & 0,00019 \\
Wetzel & 0,04122 & 0,006 \\
Arteb & 0,03968 & $-0,01706$ \\
Caraíba metais & 0,01011 & $-0,04682$ \\
Chiarelli & 0,06625 & $-0,12286$ \\
Gol & $-0,10487$ & $-0,27351$ \\
Gol & 0,53278 & 0,31147 \\
Catagueses & 0,32954 & 0,29723 \\
Teka & 0,05825 & 0,05478 \\
Predileto & $-0,24695$ & $-0,28906$ \\
Invepar & 0,08867 & 0,08682 \\
Parmalat & $-0,10487$ & $-0,27351$ \\
São Martinho & $-0,17669$ & $-0,19202$ \\
Americanas & 0,12291 & 0,0912 \\
Banco Cruzeiro & 0,01893 & $-0,04536$ \\
Energisa & 0,04995 & $-0,04038$ \\
Inepar Energia & 0,06083 & 0,03089 \\
CEEE-D & 0,00901 & 0,00766 \\
I & 0,13902 & 0,13711 \\
Média & $\mathbf{0 , 9 3 7 3 8}$ & $\mathbf{0 , 2 7 7 2 3}$ \\
\hline
\end{tabular}

Nota. Fonte: Dados da pesquisa.

De acordo com a Tabela 5, 19 empresas que republicaram suas demonstrações contábeis reduziram o índice ROA; as demais empresas mantiveram seus índices inalterados após a republicação. 
Republicação das Demonstrações Contábeis: Uma Análise sob a perspectiva dos indicadores de desempenho

Sabrina da Silva Campos, Roberto Miranda Pimentel Fully, Aucione Aparecida Barros Guimarães

Tabela 6

Reduções no índice ROE

\begin{tabular}{lcc}
\hline \multicolumn{1}{c}{ Empresas } & Antes da republicação & ROE \\
Duke & 0,14958 & Após a republicação \\
Celesc & 0,04278 & 0,00976 \\
Celesc & 0,05413 & $-0,09609$ \\
Varig & 1,03714 & 0,05173 \\
Varig & 0,81159 & $-0,40186$ \\
Wetzel & 0,14923 & $-1,00328$ \\
Caraíba metais & 0,11166 & 0,03977 \\
Gol & 0,31628 & $-0,65437$ \\
Catagueses & 0,07905 & 0,30542 \\
Cia. Cataguases & 0,1185 & 0,07476 \\
Invepar & $-0,88687$ & 0,0852 \\
Parmalat & $-1,01602$ & $-1,97021$ \\
Mendes Júnior & 0,14296 & $-1,90598$ \\
São Martinho & 0,36265 & $-0,01147$ \\
Americanas & 0,01893 & 0,30407 \\
Banco Cruzeiro & 0,16745 & $-0,04536$ \\
Estrela & 0,12791 & 0,00281 \\
CEEE-D & 0,09515 & 0,09264 \\
CEEE-GT & $-0,12069$ & 0,09264 \\
DTCOM & $-0,2017$ & $-0,13629$ \\
$\Sigma$ & $\mathbf{1 , 5 5 9 7 1}$ & $-0,2995$ \\
Média & $\mathbf{0 , 1 4 8 5 4 4}$ & $\mathbf{- 5 , 4 6 5 6 1}$ \\
\hline
\end{tabular}

Nota. Fonte: Dados da pesquisa.

De acordo com a Tabela 6, 20 empresas que republicaram suas informações contábeis reduziram o índice ROE, ou seja, tiveram o retorno sobre o Patrimônio Líquido reduzido. As demais empresas (28\%) mantiveram seus índices inalterados após as republicações. 
Republicação das Demonstrações Contábeis: Uma Análise sob a perspectiva dos indicadores de desempenho

Sabrina da Silva Campos, Roberto Miranda Pimentel Fully, Aucione Aparecida Barros Guimarães

Tabela 7

Reduções no índice ET

\begin{tabular}{lcc}
\hline \multicolumn{1}{c}{ Empresas } & Antes da republicação & Após a republicação \\
\hline Varig & 1,15198 & 0,99657 \\
Varig & 1,78021 & 1 \\
Mendes Júnior & 0,83004 & 0,57191 \\
São Martinho & 1,38425 & 0,94169 \\
Energisa & 1,14545 & 1,02576 \\
Estrela & 0,84901 & 0,81718 \\
Hotéis Othon & 0,72175 & 0,68483 \\
Inepar Energia & 1,91482 & 1,75885 \\
$\Sigma$ & $\mathbf{9 , 7 7 7 5 1}$ & $\mathbf{7 , 7 9 6 7 9}$ \\
\hline Média & $\mathbf{2 , 1 7 2 7 8}$ & $\mathbf{1 , 7 3 2 6 2}$ \\
\hline
\end{tabular}

Nota. Fonte: Dados da pesquisa.

Analisando a Tabela 7 , somente 08 empresas que republicaram reduziram seu índice de endividamento; as demais empresas (22\%) mantiveram seus índices inalterados após às republicações.

A partir das análises das variáveis estatísticas e quadros comparativos, foi possível constatar os impactos negativos nos índices. Observa-se que os percentuais de reduções nos índices de rentabilidade foram maiores que os percentuais de aumentos. Já no índice de Endividamento Total, o percentual de aumento foi maior que o percentual de redução.

\section{CONSIDERAÇÕES FINAIS}

De acordo com Callen, Livnet e Segal (2005), o gerenciamento de resultados permite que gerentes oportunistas manipulem os resultados com o intuito de mascarar o desempenho da entidade, evidenciando o que Ihes for conveniente, escondendo a realidade financeira, econômica e patrimonial da entidade em determinado momento, incorrendo em erros e contribuindo para a assimetria informacional, levando as entidades a republicarem suas demonstrações. 
Republicação das Demonstrações Contábeis: Uma Análise sob a perspectiva dos indicadores de desempenho

Sabrina da Silva Campos, Roberto Miranda Pimentel Fully, Aucione Aparecida Barros Guimarães

Esta pesquisa não tinha como objetivo evidenciar o erro nas demonstrações que implicaram as republicações; no entanto, o gerenciamento de resultados compromete as informações contidas nos demonstrativos contábeis divulgados, podendo impactar na decisão dos investidores.

O objetivo da pesquisa foi analisar os impactos das republicações nos índices ROA, ROE e Endividamento Total no período de 2000 a 2013. Foram constatados impactos negativos nos índices, devido a um aumento significativo no índice ET (8\%), e reduções no índice ROE (22,9\%). No índice ROA, foi constatado aumento $(34,5 \%)$, no entanto, o índice se manteve negativo.

Os resultados gerais do estudo estão em concordância com a revisão teórica desenvolvida nesta pesquisa, pois todos os estudos evidenciados indicaram impactos negativos após as republicações. Portanto, foi constatado que as republicações afetam negativamente as empresas, contribuindo para a perda de confiança dos investidores.

Para pesquisas futuras, podem ser estudados outros índices de desempenho e rentabilidade, como também analisar os impactos das republicações no valor das ações, nos custos de capital, na confiança dos investidores, se as republicações têm relações com o nível de governança corporativa, auditoria ou tamanho da empresa.

\section{REFERÊNCIAS}

Anderson, K. L., \& Yohn, T. L. (2002). The effect of 10-k restatements on firme value, information asymmetries, and inventors' realiance on earnings. Social Science Research Network. Recuperado de: <http://papers.ssrn.com>.

Angeli, P. P. T. (2008). Republicação das Demonstrações Contábeis: uma análise dos índices ROA, ROE e endividamento total em empresas brasileiras no período de 2000 a 2005. (Dissertação de Mestrado em Ciências Contábeis). Fundação Instituto Capixaba de Pesquisas em Contabilidade, Economia e Finanças, Vitória, ES. Recuperado em 19 novembro, 2015, de: $<$ http://www.fucape.br/_admin/upload/prod_cientifica/Dissertaca0\%20Pedro\%20Pau lo\%20T orri.pdf $>$.

Assaf Neto, A. (2006). Finanças Corporativas e Valor. (2a ed.). São Paulo: Atlas. 
Republicação das Demonstrações Contábeis: Uma Análise sob a perspectiva dos indicadores de desempenho

Sabrina da Silva Campos, Roberto Miranda Pimentel Fully, Aucione Aparecida Barros Guimarães

Bischoff, J., Finley, J., \& Leblanc, D. (2008). Financial statement restatements: causes and effects. Tenessee CPA Journal.

Brasil. Lei n.o 11.638, de 28 de Dezembro de 2007. Dispõe sobre a elaboração e divulgação das demonstrações contábeis. Recuperado de: <http://www.planalto.gov.br/ccivil_03/_ato2007-2010/2007/lei/l11638.htm>.

Brasil. Lei $n . \circ$ 6.404, de 15 de dezembro de 1976. Dispõe sobre as Sociedades por Ações. Recuperado em 22 agosto, 2015, de: <http://www.planalto.gov.br/ccivil_03/Leis/L6404consol.htm>.

Callen, J. L., Livnat J., \& Segal, D. (2005). Accounting Restatements: Are They Always Bad News for Investors? Social Science Research Network. Recuperado de: $<$ http://papers.ssrn.com>.

Chen, H., Tang, Q., Jiang, Y., \& Lin, Z. (2010). The role of international financial reporting standards in accounting quality: Evidence from the European Union. Journal of International Financial Management \& Accounting, 21, 220-278.

Comitê de Pronunciamentos Contábeis - CPC 26. Apresentação das Demonstrações Contábeis. Recuperado de: http://static.cpc.mediagroup.com.br/Documentos/312_CPC_26_R1_rev\%2006. pdf>.

Daske, H., Hail, L., Leuz, C., \& Verdi, R. S. (2008). Mandatory IFRS Reporting Around the World: Early Evidence on the Economic Consequences. ECGI - Finance Working Paper, 198, Chicago GSB Research Paper, 12. <http://paper.ssrn.com>.

Dichev, I. D. (2002). The quality of accruals and earnings: the role of accrual estimation errors. The Accounting Review, 77(4), Supplement, 35-59.

Ewert, R., \&. Wagenhofer, A. (2005). "Economic Effects of Tightening Accounting Standards to Restrict Earnings Management." The Accounting Review, 80, 11011124.

Hribar, P., \& Jenkins, N. T. (2004). The effect of accounting restatements on earnings revisions and the estimated cost of capital. Review of Accounting Studies, 9( 2-3), 337-356.

IAS 1 - Apresentação das Demonstrações Financeiras. Recuperado de: $<$ www.ifrs.org $>$. 
Republicação das Demonstrações Contábeis: Uma Análise sob a perspectiva dos indicadores de desempenho

Sabrina da Silva Campos, Roberto Miranda Pimentel Fully, Aucione Aparecida Barros Guimarães

Lambert, R., Leuz, C., \& Verrecchia, R. (2007). "Accounting Information, Disclosure, and the Cost of Capital." Journal of Accounting Research 45, 385-420.

Larson, R., Farber, B. (2010). Elementary Statistics. Tradução: Luciane Ferreira Pauleti Viana. (4a. ed.). São Paulo: Pearson Prentice Hall.

Lassen, A. H., Gertsen, F., \& Riis, J. O. (2006, December). Nexus of Corporate Entrepreneurship and Radical Innovation. Creativity and Innovation Management, 15(4), 359-372. <http://papers.ssrn.com>.

NBC TG 26(R3) - Apresentação das Demonstrações Contábeis. Recuperado em 18 maio, 2015, de: <www.cfc.org.br>.

NBC TG 40(R1) - Instrumentos Financeiros: Evidenciação. Recuperado em 17 novembro, 2015, de http://www.cfc.org.br.

NBC TG ESTRUTURA CONCEITUAL - Estrutura Conceitual para Elaboração e Divulgação de Relatório Contábil-Financeiro. Recuperado em 17 novembro, 2015, de http://www.cfc.org.br.

Palmrose, Z. V., Richardson, V. J., \& Scholz, S. (2004, fevereiro). Determinants of market reactions to restatements announcements. Journal of Accounting and Economics, 37(1), 59-89.

Pires, C. O., Decourt, R. F., Camargo, C. U. O., \& Siebel, V. (2012). Os impactos da fase final de transição para o IFRS no Brasil. Anais do Congresso Virtual Brasileiro de Administração, IX Convibra, 9.

Schipper, K. (2003, março). Principles-based accounting standards. Accounting Horizons. 17(1), 61-72.

Silva, S. M. de B. (1999). Evidenciação Contábil de Instituições Bancárias no Brasil. Anais da 8 $8^{a}$ Semana da Contabilidade do Banco Central do Brasil - Bacen: " Internacionalização da Economia e Desafios e Perspectivas da Contabilidade", Brasília, Brasil, 137-160, 8.

Soderstrom, N. S., \& Sun, K. J. (2007). IFRS Adoption and Accounting Quality: A Review. European Accounting Review, Forthcoming. Recuperado de: $<$ http://papers.ssrn.com>.

Zang, A. (2012). Evidence on the trade-off between real activities manipulation and accrualbased earnings management. The Accounting Review 87 (2), 675-670. 
Republicação das Demonstrações Contábeis: Uma Análise sob a perspectiva dos indicadores de desempenho

Sabrina da Silva Campos, Roberto Miranda Pimentel Fully, Aucione Aparecida Barros Guimarães

Data de Submissão: 21/12/2018

Data de Aceite: 08/04/2020 